\title{
Audiogram of a Cook Inlet beluga whale (Delphinapterus leucas)
}

T. Aran Mooney, Manuel Castellote, Ian Jones, Natalie Rouse, Teri Rowles, Barbara Mahoney, and Caroline E. C. Goertz

Citation: The Journal of the Acoustical Society of America 148, 3141 (2020); doi: 10.1121/10.0002351

View online: https://doi.org/10.1121/10.0002351

View Table of Contents: https://asa.scitation.org/toc/jas/148/5

Published by the Acoustical Society of America

\section{ARTICLES YOU MAY BE INTERESTED IN}

On the use of the Lloyd's Mirror effect to infer the depth of vocalizing fin whales

The Journal of the Acoustical Society of America 148, 3086 (2020); https://doi.org/10.1121/10.0002426

Evaluating temporary threshold shift onset levels for impulsive noise in seals

The Journal of the Acoustical Society of America 148, 2973 (2020); https://doi.org/10.1121/10.0002649

How loud is the underwater noise from operating offshore wind turbines?

The Journal of the Acoustical Society of America 148, 2885 (2020); https://doi.org/10.1121/10.0002453

Whistles of Atlantic spotted dolphin from a coastal area in the southwestern Atlantic Ocean

The Journal of the Acoustical Society of America 148, EL420 (2020); https://doi.org/10.1121/10.0002637

Weddell seals produce ultrasonic vocalizations

The Journal of the Acoustical Society of America 148, 3784 (2020); https://doi.org/10.1121/10.0002867

Sound detection by Atlantic cod: An overview

The Journal of the Acoustical Society of America 148, 3027 (2020); https://doi.org/10.1121/10.0002363

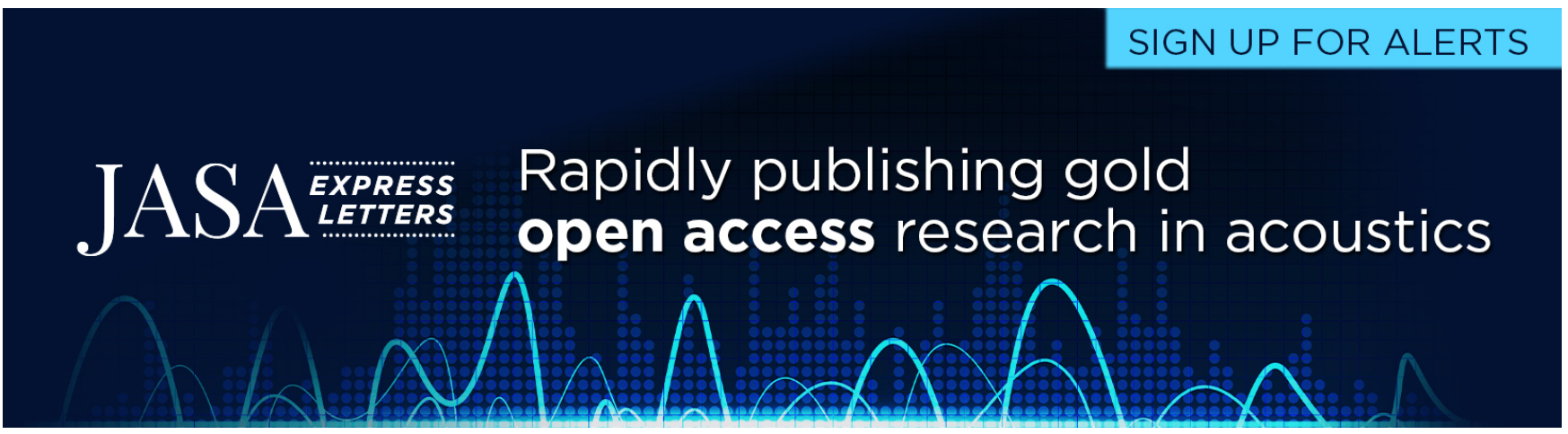




\title{
Audiogram of a Cook Inlet beluga whale (Delphinapterus leucas)
}

\author{
T. Aran Mooney, ${ }^{1, a)}$ Manuel Castellote, ${ }^{2, b)}$ lan Jones, ${ }^{1, c)}$ Natalie Rouse, ${ }^{3}$ Teri Rowles, ${ }^{4}$ Barbara Mahoney, ${ }^{5}$ \\ and Caroline E. C. Goertz ${ }^{3}$ \\ ${ }^{1}$ Biology Department, Woods Hole Oceanographic Institution, Woods Hole, Massachusetts 02543, USA \\ ${ }^{2}$ Cooperative Institute for Climate, Ocean, and Ecosystem Studies, University of Washington, 3737 Brooklyn Avenue Northeast, \\ Seattle, Washington 98105, USA \\ ${ }^{3}$ Alaska SeaLife Center, Seward, Alaska 99664, USA \\ ${ }^{4}$ Marine Mammal Health and Stranding Response Program, Office of Protected Resources, National Oceanic and Atmospheric \\ Administration, National Marine Fisheries Service, Silver Spring, Maryland 20910, USA \\ ${ }^{5}$ Protected Resources Division, Alaska Regional Office, National Oceanic and Atmospheric Administration, \\ National Marine Fisheries Service, Anchorage, Alaska 99513, USA
}

\begin{abstract}
:
Noise is a stressor to wildlife, yet the precise sound sensitivity of individuals and populations is often unknown or unmeasured. Cook Inlet, Alaska belugas (CIBs) are a critically endangered and declining marine mammal population. Anthropogenic noise is a primary threat to these animals. Auditory evoked potentials were used to measure the hearing of a wild, stranded CIB as part of its rehabilitation assessment. The beluga showed broadband $(4-128 \mathrm{kHz})$ and sensitive hearing $(<80 \mathrm{~dB})$ for a wide-range of frequencies $(16-80 \mathrm{kHz})$, reflective of a healthy odontocete auditory system. Data were similar to healthy, adult belugas from the comparative Bristol Bay population (the only other published data set of healthy, wild marine mammal hearing). Repeated October and December 2017 measurements were similar, showing continued auditory health of the animal throughout the rehabilitation period. Hearing data were compared to pile-driving and container-ship noise measurements made in Cook Inlet, two sources of concern, suggesting masking is likely at ecologically relevant distances. These data provide the first empirical hearing data for a CIB allowing for estimations of sound-sensitivity in this population. The beluga's sensitive hearing and likelihood of masking show noise is a clear concern for this population struggling to recover.
\end{abstract}

https://doi.org/10.1121/10.0002351

(Received 24 February 2020; revised 14 September 2020; accepted 5 October 2020; published online 25 November 2020)

[Editor: Laura N. Kloepper]

Pages: $3141-3148$

\section{INTRODUCTION}

Belugas use sound rather than sight for many important functions. As a high latitude species they are often found in turbid coastal waters and waters where darkness and sea ice extends for many months. Thus, sound and hearing play crucial roles in navigation, feeding, predator avoidance, and social communication. Consequently, changes in ambient noise levels may have a large impact on their ability to thrive. Anthropogenic noise will increasingly threaten the northern high-latitude seas and habitats, as the Northwest Passage remains seasonally open due to shrinking ice coverage, which will allow significant increases in shipping along Alaska's North Slope as well as concurrent seismic exploration for hydrocarbon material concentrated offshore (Beauregard-Tellier, 2008).

The CIB population was listed as endangered under the U.S. Endangered Species Act in 2008 after a rapid decline attributed to the unregulated subsistence hunt (National

\footnotetext{
a)Electronic mail: amooney@whoi.edu, ORCID: 0000-0002-5098-3354.

${ }^{b)}$ Also at: Marine Mammal Laboratory, Alaska Fisheries Science Center, National Marine Fisheries Service, Seattle, WA 98115, USA

${ }^{c}$ Also at: MIT-WHOI Joint Program in Oceanography/Applied Ocean Science and Engineering, Cambridge, MA 02139, USA.
}

Marine Fisheries Service, 2008). Ten years later, this population of 279 whales continues with a steady decline of $-2.3 \%$ per year, over the last 10 years (Shelden and Wade, 2019). Unless the factors that are impeding recovery are determined and mitigated, this population of whales will be lost (Hobbs et al., 2006).

A considerable body of research documents anthropogenic noise impacts on odontocete communication and habitat use, specifically spatial displacement (Nowacek et al., 2007), which cannot be excluded for CIBs (Small et al., 2017). Cook Inlet is perhaps the most densely populated and fastest growing embayment in Alaska. Increased industrial and commercial activities, habitat degradation, and global warming/climate change are threatening the CIB population and its critical habitat. Massive infrastructure projects in Anchorage and other coastal towns typically have the potential to directly impact CIB's critical habitat. Oil and gas exploration and production, commercial fisheries, increasing commercial maritime traffic, industrial development, and the underwater noise generated by all these activities are damaging and modifying CIB habitat, contributing to its lack of recovery.

Man-made sources of noise in CI include large and small vessels, aircraft, oil and gas operations marine seismic 
surveys, pile driving, and dredging (Blackwell and Greene, 2002; Castellote et al., 2018). This noise may result in disturbance and harassment, altering movements or avoidance of areas important to their life history, and/or causing chronic effects such as temporary or permanent damage to a whale's hearing (Southall et al., 2008). Geophysical seismic activity has been described as one of the loudest man-made underwater noise sources, with the potential to harass or harm the CIBs, including temporary or permanent hearing loss (National Marine Fisheries Service, 2008). Permanent sources of noise in some areas of the CIB critical habitat, such as shipping, oil and gas production, or dredging, introduce significant noise with the potential for negative effects due to chronic exposure (Castellote et al., 2018). Even low levels of noise may have biological impacts by "masking" (e.g., hiding or overwhelming) important communication signals, influencing communication behaviors and disrupting foraging (Jensen et al., 2009; Lusseau et al., 2009; Fouda et al., 2018; Wisniewska et al., 2018).

A major detraction to determine noise effects on this population is our poor understanding of hearing sensitivity for any CIB whale. With limited hearing data in many marine mammal populations, noise effects may be considered tenuous because insufficient information limits extrapolations between species and populations. Auditory differences among populations exist among some frog species. For example, auditory tuning (neuronal response amplitude at particular frequencies) is related to sexual selection, with increased responses for certain call frequencies and population-based female preference can play a role in selecting male call frequency (Ryan et al., 1992). Similar population-based auditory sensitivity tuning differences appear based upon background noise conditions of local habitats (Witte et al., 2005). Chemical pollution (and noise pollution) may impact auditory hair cells (Choi and Grandjean, 2008; Low and Higgs, 2015) and presumably this could also influence population-based differences. Such data suggests population based auditory studies are important to assess the sensory health of at-risk populations such as the CIB.

Studies on captive belugas established baseline auditory information, including the audiogram, masked hearing thresholds, temporary threshold shift phenomena, auditory filter shapes, and hearing pathways (Awbrey et al., 1988; Klishin et al., 2000; Finneran et al., 2002; Mooney et al., 2008). Hearing studies on wild, healthy adult Bristol Bay (BB) belugas offer a key comparison because these animals reside in somewhat pristine environment (Castellote et al., 2014; Mooney et al., 2016; Mooney et al., 2018a; Mooney et al., 2018b). The audiograms and variability in sensitivity offer a key baseline from which there may be comparisons to other belugas from other populations.

In 2017, we had the opportunity to diagnostically assess the hearing of a live stranded CIB calf. We used the same physiological auditory evoked potentials (AEPs) method as in the BB studies, which offers a direct comparison and evaluates for hearing loss. The AEP method involves measuring small voltages generated by the peripheral and central auditory structures in response to various sound stimuli (Supin et al., 2001). This technique compares to traditional behavioral methods (Yuen et al., 2005), yet has the advantage of allowing rapid threshold measurements from untrained animals to diagnostically assess auditory health (Nachtigall et al., 2005; Mooney et al., 2006). Beluga responses are acquired non-invasively from the surface of the skin using electroencephalography (EEG) recording electrodes embedded in latex suction cups. AEPs have been applied to measure hearing in diverse taxa, including invertebrates, fish, birds, and mammals, as well as human infants (Kenyon et al., 1998; Brittan-Powell et al., 2002; Hall, 2007; Mooney et al., 2010). In marine mammals, AEP systems are a well-established means to examine hearing, quickly and non-invasively.

The hearing results from the CIB calf were compared to BB beluga data (Castellote et al., 2014; Mooney et al., 2018a; Mooney et al., 2018b). The hearing tests were diagnostic, one of several measurements collected that describes the health of the CIB calf. Similar hearing evaluations were completed on other odontocetes (Nachtigall et al., 2005; Finneran et al., 2009; Mann et al., 2010; Pacini et al., 2010). For this CIB calf, the hearing evaluation was done just days after the reported stranding to determine its immediate hearing abilities. A follow-up examination occurred two months after medical treatment, as part of his diagnostic evaluation for possible release.

\section{METHODS}

\section{A. Stranding summary}

Mid-afternoon, on 30 September 2017, a gray beluga whale was observed above the waterline in Trading Bay, south of McArthur River, on the west side of Cook Inlet $(60.88 \mathrm{~N}, 151.73 \mathrm{~W})$. Upon closer inspection, it was a live calf with moderate external physical trauma. Attempts to encourage swimming into the inlet were unsuccessful and no other belugas were visible in the area. The calf was assessed to be a new male calf with minor injuries, and because it was too young to survive on his own, the recommendation was to attempt rehabilitation. Rescue was authorized by the National Oceanographic and Atmospheric Administration. This calf was transported by helicopter to Anchorage and by truck to the Alaska SeaLife Center, Seward, for immediate care and rehabilitation; it was also the location of this study. Based on morphological characteristics (length $162 \mathrm{~cm}$ and $64 \mathrm{~kg}$ ) and physiological parameters, the calf was aged at 17 days (anywhere between 10 to 30 days old). He was slightly malnourished, traumatized, and at risk to develop infections secondary to the stranding event due to aspirating sea water and his immature immune system. Pneumonia was confirmed by a computed tomography (CT) scan. While under care the beluga developed a pneumothorax and various gastrointestinal problems, including constipation and bloat. To treat these conditions the beluga was treated with several medications including 
antibiotics (including an aminoglycoside), antifungals, and gastrointestinal support (Goertz et al., 2019). After seven weeks, the beluga calf was considered recovered from problems present at admittance and all medications were stopped. Because of his age and inability to survive on his own, he was declared non-releasable by the National Marine Fisheries Service, National Oceanic and Atmospheric Administration and placed in another zoological facility (SeaWorld, Texas) with other beluga whales for long-term care.

Hearing measurements were made on 4 and 5 October, and 5 and 6 December, 2017 using AEP recording methods, a means to rapidly, passively, and non-invasively, examine hearing (Supin et al., 2001; Houser and Finneran, 2006; Finneran et al., 2007; Nachtigall et al., 2007; Mooney et al., 2012). All hearing examinations were conducted in-water, where the calf was gently secured by gently holding the animal with its head free (Fig. 1). Water depths were $1 \mathrm{~m}$ in both rehabilitation pools where the data were collected. Data acquisition, calibrations, and analyses were designed to follow the previous beluga AEP hearing studies and American National Standards Institute (ANSI) standards for measuring odontocete audiograms (Castellote et al., 2014; ANSI, 2018; Mooney et al., 2018b). During each set of tests, hearing data were collected for two consecutive days (a portion of the audiogram each day). This limited the examination time that the calf needed to be still. As the calf's health improved between October and December, he was moved on 7 November from the smaller, indoor rehabilitation pool to a larger outdoor pool (Fig. 1). Calibrations of the audiogram tones and background noise measurements were conducted in each test tank.

\section{B. Stimulus presentation and evoked potential recording}

Once the beluga calf was properly stationed, three custom-built silicone suction cups (KE1300T, Shin-Etsu, Tokyo, Japan) with embedded gold electrodes (Grass Technologies, Warwick, RI) were attached using conductive electrode gel (Signagel, Parker Laboratories, Fairfield, NJ). An active (non-inverting) electrode was placed along the midline of the animal 3-4 cm behind the blowhole. A reference electrode was placed on the dorsal peduncle, and a ground electrode was placed on the animal's tail fin. The electrodes were connected to a biological amplifier (CP511, Grass Technologies) which amplified all responses $10000-$ fold and bandpass filtered them from 300 to $3000 \mathrm{~Hz}$. A second Krohn-Hite $300-3000 \mathrm{~Hz}$ bandpass filter further conditioned the signal. This bioamplifier was connected to a BNC Breakout Box (2110, National Instrument, Austin, TX) and a PCMCIA-6062E data acquisition card implemented in a laptop computer. Using a custom LabView program (National Instruments), the data acquisition card converted the analog signal to a digital record at a $16 \mathrm{kHz}$ sampling rate. All data were stored on the laptop computer.

Acoustic stimuli were created using the same custom LabView program, laptop, and data acquisition card. Outgoing signals were produced at a $512 \mathrm{kHz}$ update rate for signals at $100 \mathrm{kHz}$ and $750 \mathrm{kHz}$, for higher frequency tones. Signals tested included: 4, 5.6, 8, 11.2, 16, 22.5, 32, 45, 54, $80,100,120,128$, and $150 \mathrm{kHz}$. At the October test, no responses were detected at $128 \mathrm{kHz}$ and thresholds were clearly increasing (at 100 and $120 \mathrm{kHz}$ ), thus we did not test higher frequencies. Testing the lower frequencies allowed for comparisons to previous beluga studies. Signal amplitudes were controlled using a HP 350D (Palo Alto, CA) attenuator and projected to the animal through a custom "jawphone" or suction-cup transducer. This consisted of a Reson 4013 transducer (Slangerup, Denmark) implanted in a custom-built silicone suction cup. The transducer was attached to the whale using the electrogel to eliminate reflective air gaps between the cup and the calf's skin.

The CIB was presented with broadband clicks at the start of each examination. Subsequently, all stimuli were amplitude modulated tones. All signals were presented in $20 \mathrm{~ms}$ bouts at a $20 \mathrm{~s}^{-1}$ rate. Carrier signals within the bout were modulated (tones) or presented (clicks) at a rate of $1 \mathrm{kHz}$. The individual click stimuli were $20 \mu \mathrm{s}$ in duration.
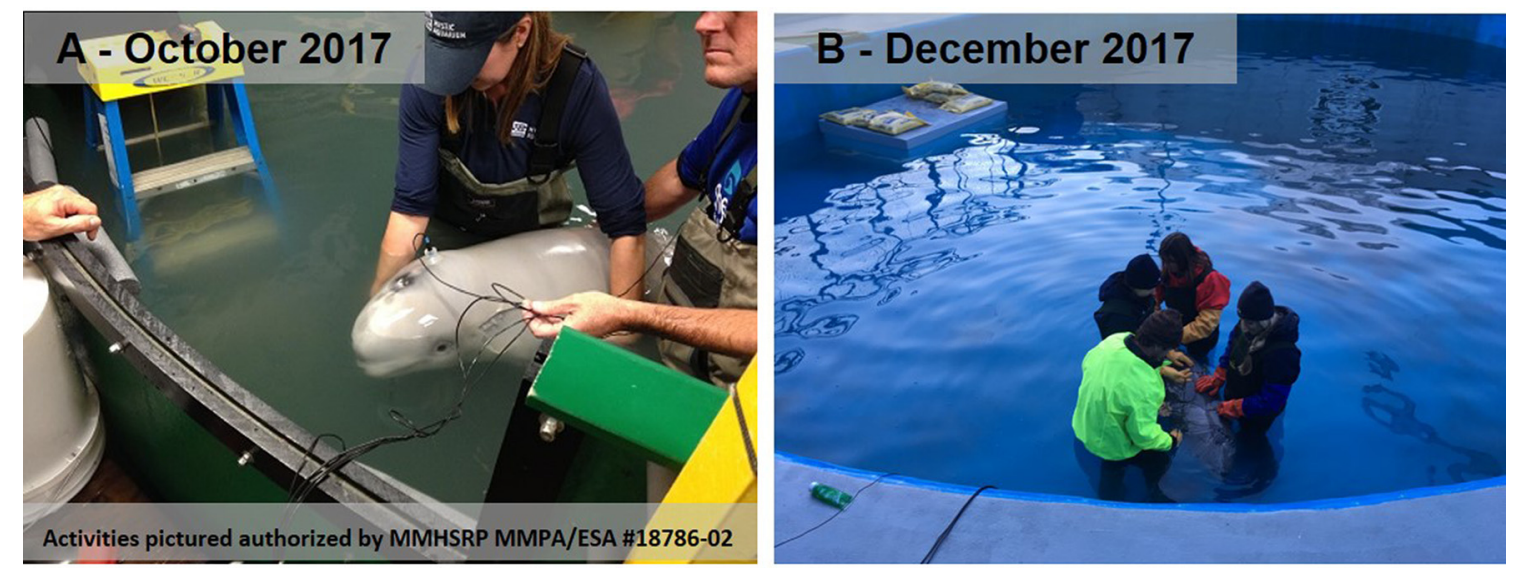

FIG. 1. (Color online) Diagnostic hearing evaluations of the Cook Inlet beluga. The studies were conducted (A) in an indoor rehabilitation facility in October 2017 and (B) a larger, outdoor facility in December 2017. In this photo the older beluga molted to a darker grey color. He is located between the rehabilitation staff, facing the wall. 
Evoked response recordings were $30 \mathrm{~ms}$ duration and began to coincide with stimulus presentation. Stimuli were presented 1000 times for each sound level and a corresponding response was collected for each sound presentation. These 1000 responses were averaged using the custom software and stored for later data analyses. The total number of stimuli and sweeps is relatively standard for odontocetes because it establishes a robust response while averaging down the background noise to a relatively low level (Nachtigall et al., 2007). A record for a particular frequency and sound level is then acquired in $50 \mathrm{~s}$ and thresholds are obtained in just a few minutes. These procedures were essentially identical to earlier beluga tests (Castellote et al., 2014; Mooney et al., 2018b).

\section{Calibrations and data analysis}

Suction-cup transducer stimuli were calibrated in the water in both test tanks. Received measurements were made using a DMON (Kaplan et al., 2015) recording system. The projector and receiver were placed $35 \mathrm{~cm}$ apart at $15 \mathrm{~cm}$ depth. This was the approximate distance of auditory bulla to jawphone transducer placed at the rostrum tip, estimated from diagnostic CT scans. The use of the short-duration sinusoidally amplitude modulated (SAM) tone sweeps (i.e., several $\mathrm{ms}$ ) and relatively low sound levels (i.e., reflections were significantly attenuated relative to the direct $1 \mathrm{~m}$ path) reduced the interference of overlapping standing waves and facilitated the calibration. For each frequency the received levels were calculated in $\mathrm{dB}_{\mathrm{RMS}}$ re $1 \mu \mathrm{Pa}$ over the $20 \mathrm{~m}$ tone pip duration at one attenuation setting. Proper attenuation was later checked by recording tones at multiple attenuation levels and verifying received levels matched predicted attenuation values. Sound pressure levels of the clicks were measured using $\mathrm{V}_{\mathrm{p}-\mathrm{p}}$ (Au 1993). Hereafter, dB levels of click sound pressure levels (SPLs) are presented in $\mathrm{dB}_{\mathrm{p}-\mathrm{p}}$ re: 1 $\mu \mathrm{Pa}$ and $\mathrm{SAM}$ tone $\mathrm{dB}$ are presented in $\mathrm{dB}_{\mathrm{RMS}}$ re: $1 \mu \mathrm{Pa}$.

Response waveforms and power spectra were observed during the evaluation and sound levels were then decreased in steps of 5-10 dB, until responses were no longer visually detectable for 2-3 trials. However, actual threshold estimates were calculated offline, where a $16-\mathrm{ms}$ portion of the response was fast-Fourier transformed (FFT) (256 sample points) and viewed in the frequency spectrum. The magnitude of the envelope following response was reflected by a peak in the FFT at the $1 \mathrm{kHz}$ modulation rate (Supin and Popov, 1995). Thresholds were then calculated following two methods, a regression based method used in other beluga hearing-test studies (Mooney et al., 2008; Mooney et al., 2018b) and an $F$-statistic method (Dobie and Wilson, 1993; Finneran et al., 2007). With respect to the regression based methods, briefly, the FFT-values at the modulation frequency were plotted as response intensity against SPL of the stimulus at a given frequency. A regression line addressing the data points was extended to hypothetical zero (horizontal axis intercept of the regression), the theoretical point where there would be no response to the stimulus. The stimulus SPL value corresponding to the estimated zero response, was the estimated hearing threshold for each of the frequencies presented to the animal as described in Supin et al. (2001). From these thresholds, audiograms could then be established for each animal. Similarly, the Fstatistic method evaluates the response in the frequency domain, but here comparing the AEP amplitude at the modulation frequency $\left(f_{\mathrm{s}}\right)$ to a noise estimate obtained either from a control trial or concurrently with the AEP measurement; here we evaluated the noise power at adjacent frequencies. The ratio of the power at $f_{\mathrm{s}}$ to the noise power $\left(P_{\mathrm{n}}\right)$ provides the $F$-statistic which can be compared to a critical value $(F$-crit) using standard statistical tables. An AEP response is notable when the $F$-statistic is greater than the $(F$-crit). The threshold was taken as the last frequency at which such a response was observable.

\section{Ambient noise recordings from Cook Inlet}

We further compared the hearing thresholds of the CIBs to two types of anthropogenic noises frequently encountered in Cook Inlet. These recordings were not played to the beluga for masked hearing tests, rather they were recorded separately, prior to the hearing tests. They simply provided a comparison to estimate the potential for masking. Impact hammer pile driving noise was recorded by the mouth of Little Susitna River, May 3, 2016 at 7:39 pm. The noise was from a hydraulic impact hammer at the Port of Anchorage, $24 \mathrm{~km}$ away. The ship noise data were recorded near the mouth of Beluga River, on 16 August, 2010 at 10:25 am. The noise was likely a containership at an approximately $10 \mathrm{~km}$. We selected 20 consecutive minutes of highest amplitude sound from the passing ship. The ambient data were assessed in power spectral density dB re $1 \mu \mathrm{Pa} 2 / \mathrm{Hz}$ and in one-third octave bands, the approximate auditory filter bandwidth odontocete hearing (Erbe, 2008; Branstetter et al., 2017).

\section{RESULTS}

Evoked potential response waveforms were quite similar in shape and latency to other belugas and odontocetes previously tested. Reponses were clear and distinctly above the natural physiological noise at 20-30 dB, above an approximate threshold (Fig. 2). A series of early evoked potential waveforms were noted 3-5 ms after stimulus onset suggesting no obvious deficit to neurological structures. Primary responses to the later tones of a tone-pip train blended to form an envelope following response, which had a duration of approximately $20 \mathrm{~ms}$, the same duration as the SAM tones, but ending about $5 \mathrm{~ms}$ after the tone quieted. Response amplitudes decreased as sound levels decreased. Response latency, noted in the earliest wave latencies, also appeared to decrease as stimulus level decreased.

The CIB audiogram was measured twice, first in October 2017, four days after it was brought to Seward and again in December 2017 [Fig. 3(A)]. Background noise conditions were measured for both test tanks. The audiograms 


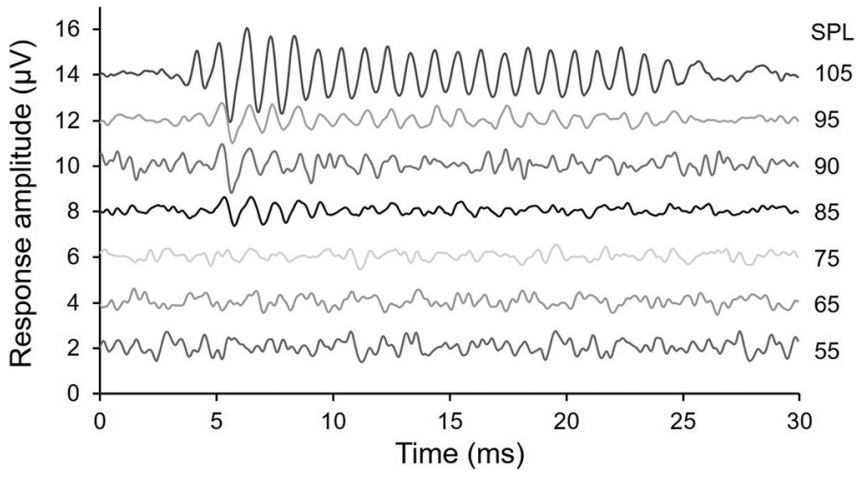

FIG. 2. Auditory evoked potential waveforms of a stranded Cook Inlet beluga calf. Test tone in this case was $80 \mathrm{kHz}$. Sound pressure levels used to evoke the responses are listed to the right.

were similar in shape and thresholds. Thresholds were lowest (below $70 \mathrm{~dB}$ ) from 16 to $80 \mathrm{kHz}$. Although thresholds increased sharply at 80 and $100 \mathrm{kHz}$, responses were not detected at $128 \mathrm{kHz}$ during the first evaluation, and not detected at $150 \mathrm{kHz}$ during both exams. Thresholds increased at a lower rate in the lower frequencies, below $16 \mathrm{kHz}$. There seemed to be a small elevation in hearing at $45 \mathrm{kHz}$. Thresholds were calculated in two manners, using two comparable objective statistical methods [Fig. 3(B)]. Further, there was no substantial difference between the regression based methods and the F-statistic. In both cases, the mean seemed to smooth out some variability between the October and December measurements, reflecting and reinforcing the need to repeat audiogram measurements on rehabilitating or research animals, a task not often done.

The general shape of the audiogram for this CIB was similar to many other tested belugas. This includes wild belugas measured in Bristol Bay [Fig. 4(A)] and many belugas found in human-care facilities [Fig. 4(B)]. To enable comparisons, the CIB thresholds also were calculated using the regression-based methods, identical to those used in the
Bristol Bay studies. The lowest mean thresholds for both the Bristol Bay and CIBs were 54 and $80 \mathrm{kHz}$. Compared to the Bristol Bay adult belugas, the CIB calf thresholds were among the more sensitive thresholds but not the lowest beluga AEP hearing thresholds measured. At the frequencies of lowest mean thresholds, 54 and $80 \mathrm{kHz}, 23 \%$ of Bristol Bay adult belugas had more sensitive thresholds than the CIB calf.

\section{DISCUSSION}

Overall, the stranded CIB calf showed comparatively low thresholds and sensitive hearing $(<80 \mathrm{~dB})$ at many frequencies across its two auditory evaluations. The audiogram shape and waveforms were generally reflective of a sensitive odontocete auditory system without substantial hearing loss. Yet the CIB calf was not quite as sensitive as some other wild belugas similarly measured. We are not certain why these differences exist. Given that the whale was quite young we did not expect presbycusis. Bristol Bay was generally a quiet test environment, free of noise from tank pumps and other laboratory features. The indoor tank did have somewhat elevated noise levels (Fig. 3), so it could be that the CIB hearing was masked by noise generated by the facility operations. However, the outdoor tank, during the December studies, was relatively quiet and the thresholds collected there were close to those measured in the indoor, noisier tank, suggesting this may be the CIB's actual hearing thresholds. Further, this variation falls within the natural variation of other hearing model taxa including bottlenose dolphins (Tursiops truncatus) and laboratory mice (Mus musculus) suggesting it is normal (Mooney et al., 2009; Ohlemiller et al., 2016).

We further compared the hearing thresholds of the CIB calf to measurements for two types of anthropogenic noise frequently encountered in upper Cook Inlet and the beluga's habitat (Fig. 5). These recordings were not played to the

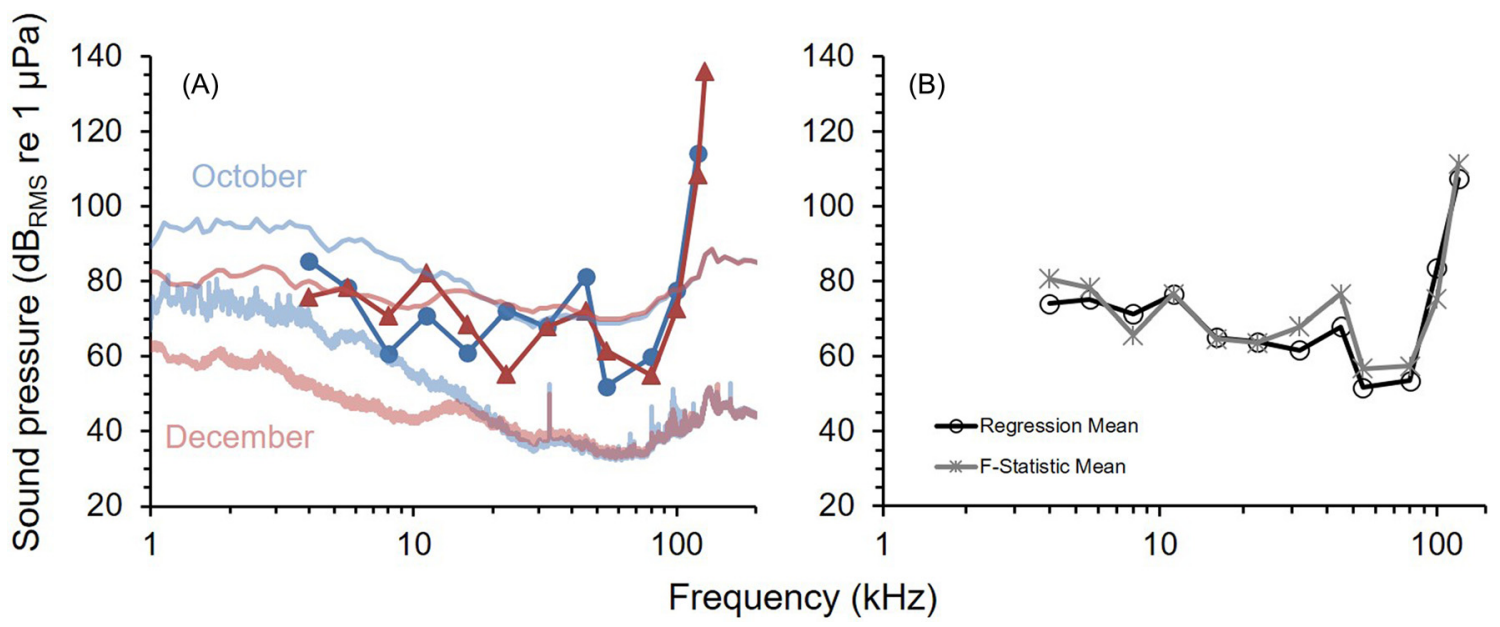

FIG. 3. (Color online) Comparison of two threshold detection methods. (A) Thresholds from October (blue circles) and December (red triangles) 2017 determined using the F-statistic method. Background noise of the test tanks were plotted in $1 / 12$ octave bands (dB re: $1 \mu$ Pa) thin blue and red lines and power spectral density dB re: $1 \mu \mathrm{Pa}^{2} / \mathrm{Hz}$ thick blue and red lines. (B) The mean of October and December thresholds determined using the F-statistic (grey, stars) and the regression of best fit (black, open circles). The mean audiograms greatly overlap in the thresholds determined. 


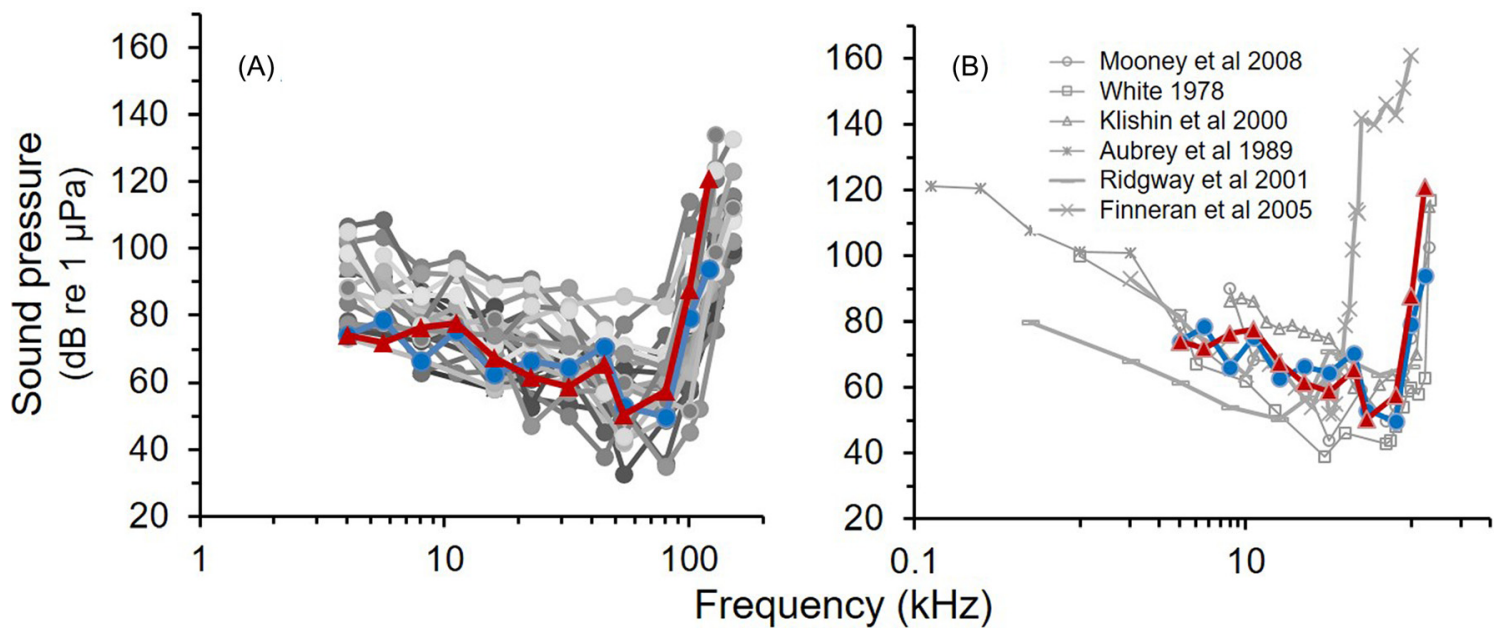

FIG. 4. (Color online) Comparison of Cook Inlet beluga audiograms to hearing thresholds of other belugas. The hearing of the CIB calf, was measured twice, in October (blue line and blue circles) and December (red line and red triangles) 2017 and are compared to the (A) hearing thresholds of wild beluga whales from Bristol Bay (Mooney et al., 2018b) and (B) beluga whales housed in laboratory or public display facilities with respective references listed in the key and are plotted in faded grey. The CIB thresholds plotted here were calculated using regression methods.

beluga for potential masked hearing tests, rather they were recorded separately, and prior to, the hearing tests. While the power spectral density values were clearly below that of auditory thresholds, noise data in one-third octave bands were substantially higher than beluga thresholds, at least at the frequency range overlap between the two noise data-sets and the beluga auditory thresholds. While we lack true masking experimental data, this overlap suggests some level of masking of near-threshold sounds would likely occur from these noise sources even at distances of several kilometers, particularly in the frequencies of communication and navigation sounds. At the very least this overlap underscores the need for auditory masking studies to determine the extent of potential masking. We would need higher frequency sample rate recordings to address potential masking of echolocation signals, and the more sensitive ranges for beluga hearing. While it seems clear that CIBs can hear these sounds, masking is a complex phenomenon with many aspects coming into play including animal orientation, temporal aspects of the masker, masking release mechanisms including abilities (or limitations) to achieve higher order processing such as discrimination (Branstetter and Finneran, 2008; Trickey et al., 2010; Branstetter et al., 2013; Dooling and Blumenrath, 2013; Erbe et al., 2016). The overlap here provides initial insight into the likelihood of masking by these noise types. Even these limited data and their overlap raises concerns for noise limiting the acoustic communication space for CIBs. Beyond masking, this may cause other effects such as disturbance, displacement, and stress. Castellote et al. (2018) presents a more exhaustive analysis of the anthropogenic noise occurrence in CIB critical habitat. Castellote et al. (2018) concluded that permanently occurring activities (e.g., shipping, dredging) exceed hearing thresholds, as well as behavioral harassment levels, on a daily basis in a significant portion of CIB critical habitat. These results confirm CIB hearing thresholds are shaped by

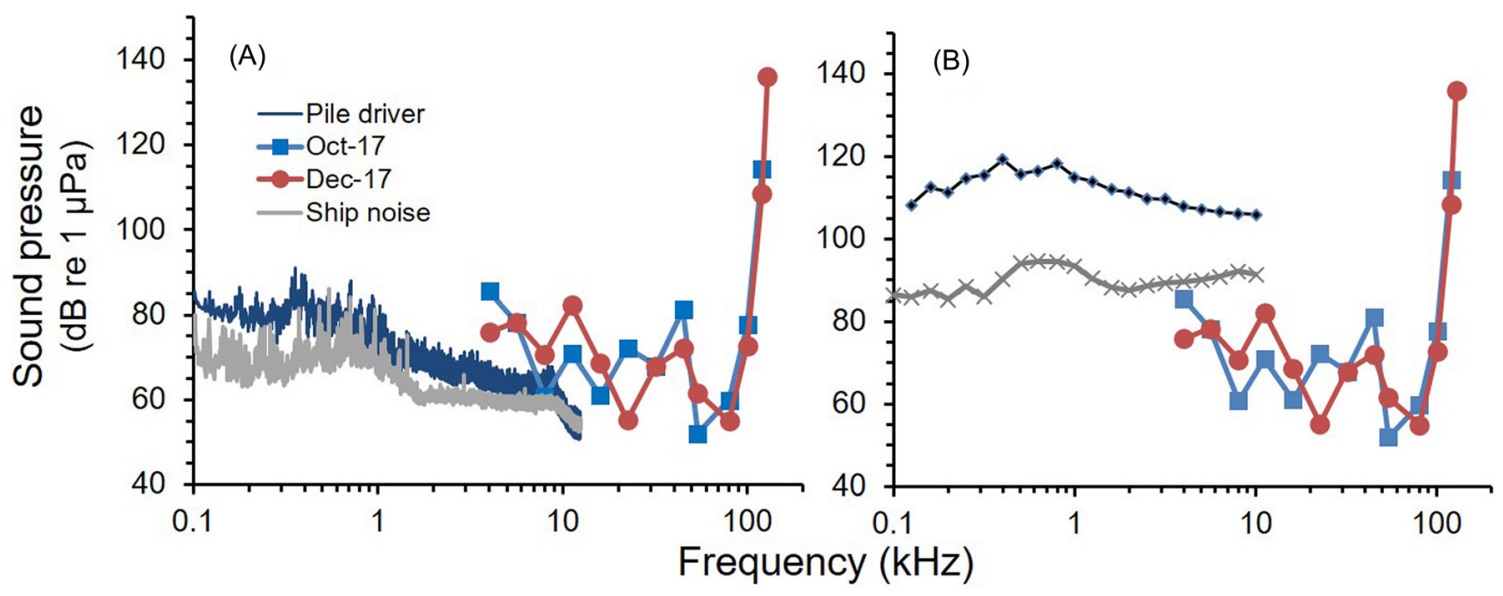

FIG. 5. (Color online) Hearing of the stranded Cook Inlet beluga compared to two types anthropogenic noise recorded in Cook Inlet. Noise is plotted in (A) $1-\mathrm{Hz}$ and (B) one-third octave band noise. In this case, the F-statistic method was used to calculate these thresholds. The CIB calf was not actually exposed to these noises. 
background noise levels across much of their hearing range, as in other beluga populations (Mooney et al., 2018a). Anthropogenic increase in background noise levels (i.e., dredging, shipping, pile driving) will unavoidably alter CIB hearing abilities.

Anthropogenic noise is encroaching on wildlife in many terrestrial and marine habitats and has a diverse array of effects from displacement to inducing physiological stress and decreasing fitness. Data on hearing provides a key step to evaluating sound-sensitivity. The CIB calf hearing appeared healthy, but human-produced noise remains a concern for all CIBs. Similar to hearing tests in wild belugas, the CIB calf AEP data were collected non-invasively, with little impact to the animal. These auditory data are invaluable, providing the first step to empirically address soundsensitivity in this endangered population. However, hearing sensitivities vary within a population. It is possible that other belugas have greater sensitivities, similar to what has been observed with Bristol Bay belugas. It is necessary to collect more audiograms of CIBs to compare to other wild and captive belugas, as well as other CIBs. This will allow us to better understand CIB hearing and their variability.

\section{ACKNOWLEDGMENTS}

We appreciate the generous support of the National Marine Fisheries Service and Dr. Deborah Fauquier, for helping make this hearing evaluation effort possible. We would like to thank the multiple teams that supported this beluga calf, including the Alaska SeaLife Center, Georgia Aquarium, Mystic Aquarium, SeaWorld, Shedd Aquarium, Texas Marine Mammal Stranding Network, and Vancouver Aquarium. The work was conducted under Permit No. MMHSRP MMPA/ESA \#18786-02 to T.R. and approved via the Institute for Animal Care and Use Protocol from the Woods Hole Oceanographic Institution. This publication was partially funded by the Joint Institute for the Study of the Atmosphere and Ocean (JISAO) under NOAA Cooperative Agreement No. NA15OAR4320063.

ANSI (2018). S3/SC1.6-2018, Procedure for Determining Audiograms in Toothed Whales Through Evoked Potential Methods (Acoustical Society of America, Melville, NY).

Awbrey, F. T., Thomas, J. A., and Kastelein, R. A. (1988). "Low-frequency underwater hearing sensitivity in belugas, Delphinapterus leucas," J. Acoust. Soc. Am. 84, 2273-2275.

Beauregard-Tellier, F. (2008). The Arctic: Hydrocarbon Resources (Parliamentary Information and Research Service, Ottawa).

Blackwell, S. B., and Greene, C. R. (2002). Acoustic Measurements in Cook Inlet, Alaska, During August 2001 (Greeneridge Sciences, Santa Barbara).

Branstetter, B. K., and Finneran, J. J. (2008). "Comodulation masking release in bottlenose dolphins (Tursiops truncatus)," J. Acoust. Soc. Am. 124, 625-633.

Branstetter, B. K., Trickey, J. S., Bakhtiari, K., Black, A., Aihara, H., and Finneran, J. J. (2013). "Auditory masking patterns in bottlenose dolphins (Tursiops truncatus) with natural, anthropogenic, and synthesized noise," J. Acoust. Soc. Am. 133, 1811-1818.

Branstetter, B. K., Van Alstyne, K. R., Wu, T. A., Simmons, R. A., Curtis, L. D., and Xitco, M. J., Jr., (2017). "Composite critical ratio functions for odontocete cetaceans,” J. Acoust. Soc. Am. 142, 1897-1900.
Brittan-Powell, E. F., Dooling, R. J., and Gleich, O. (2002). "Auditory brainstem responses (ABR) in adult budgerigars (Melopsitacus undulatus)," J. Acoust. Soc. Am. 112, 999-1008.

Castellote, M., Mooney, T. A., Hobbs, R., Quakenbush, L., Goertz, C., and Gaglione, E. (2014). "Baseline hearing abilities and variability in wild beluga whales (Delphinapterus leucas)," J. Exp. Biol. 217, 1682-1691.

Castellote, M., Thayre, B., Mahoney, M., Mondragon, J., Lammers, M. O., and Small, R. J. (2018). "Anthropogenic noise and the endangered Cook Inlet beluga whale, Delphinapterus leucas: Acoustic considerations for management," Marine Fish. Rev. 80, 63-88.

Choi, A. L., and Grandjean, P. (2008). "Methylmercury exposure and health effects in humans," Environ. Chem. 5, 112-120.

Dobie, R. A., and Wilson, M. J. (1993). "Objective response detection in the frequency domain," Electroenceph. Clin. Neurophysiol./Ev. Potent. Sec. 88, 516-524.

Dooling, R. J., and Blumenrath, S. H. (2013). "Avian sound perception in noise," in Animal Communication and Noise (Springer, Berlin), pp. 229-250.

Erbe, C. (2008). "Critical ratios of beluga whales (Delphinapterus leucas) and masked signal duration," J. Acoust. Soc. Am. 124, 2216-2223.

Erbe, C., Reichmuth, C., Cunningham, K., Lucke, K., and Dooling, R. (2016). "Communication masking in marine mammals: A review and research strategy," Marine Pollut. Bull. 103, 15-38.

Finneran, J. J., Houser, D. S., Mase-Guthrie, B., Ewing, R. Y., and Lingenfelser, R. G. (2009). "Auditory evoked potentials in a stranded Gervais' beaked whale (Mesoplodon europaeus)," J. Acoust. Soc. Am. 126, 484-490.

Finneran, J. J., Houser, D. S., and Schlundt, C. E. (2007). "Objective detection of bottlenose dolphin (Tursiops truncatus) steady-state auditory evoked potentials in response to AM/FM tones," Aquat. Mamm. 33, 43-54.

Finneran, J. J., Schlundt, C. E., Carder, D. A., and Ridgway, S. H. (2002). "Auditory filter shapes for the bottlenose dolphin (Tursiops truncatus) and the white whale (Delphinapterus leucas) derived with notched noise," J. Acoust. Soc. Am. 112, 322-328.

Fouda, L., Wingfield, J. E., Fandel, A. D., Garrod, A., Hodge, K. B., Rice, A. N., and Bailey, H. (2018). "Dolphins simplify their vocal calls in response to increased ambient noise," Biol. Lett. (UK) 14, 20180484.

Goertz, C. E., Woodie, K., Long, B., Hartman, L., Gaglione, E., Christen, D., Clauss, T., Flower, J., Tuttle, A., Richard, C., Romano, T., Schmitt, T., Otjen, E., Osborn, S., Aibel, S., Binder, T., Bonn, W. V., Castellote, M., Mooney, T. A., Dennison-Gibby, S., Burek-Huntington, K., and Rowles, T. K. (2019). "Stranded beluga (Delphinapterus leucas) calf response and care, case reports," in 2nd International Workshop on Beluga Whale Research \& Conservation, Mystic, CT (March 12-14).

Hall, J. W. (2007). The New Handbook of Auditory Evoked Potentials (Pearson Education, Boston).

Hobbs, R. C., Shelden, K. E., Vos, D., Goetz, K. T., Angliss, R. P., Brix, K., O'Corry-Crowe, G., Sims, C. L., and Smith, B. E. (2006). "Status review and extinction assessment of Cook Inlet belugas (Delphinapterus leucas)," AFSC Processed Report 2006-16.

Houser, D. S., and Finneran, J. J. (2006). "A comparison of underwater hearing sensitivity in bottlenosed dolphins (Tursiops truncatus) determined by electrophysiological and behavioral methods," J. Acoust. Soc. Am. 120, 1713-1722.

Jensen, F. H., Bejder, L., Wahlberg, M., Soto, N. A., Johnson, M., and Madsen, P. T. (2009). "Vessel noise effects on delphinid communication," Mar. Ecol. Prog. Ser. 395, 161-175.

Kaplan, M., Mooney, T., Partan, J., and Solow, A. (2015). "Coral reef species assemblages are associated with ambient soundscapes," Mar. Ecol. Prog. Ser. 533, 93-107.

Kenyon, T. N., Ladich, F., and Yan, H. Y. (1998). "A comparative study of hearing in fishes: The auditory brainstem response approach," J. Comp. Physiol. A 182, 307-318.

Klishin, V. O., Popov, V. V., and Supin, A. Y. (2000). "Hearing capabilities of a beluga whale, Delphinapterus leucas," Aquat. Mamm. 26, 212-228.

Low, J., and Higgs, D. M. (2015). "Sublethal effects of cadmium on auditory structure and function in fathead minnows (Pimephales promelas)," Fish Physiol. Biochem. 41, 357-369.

Lusseau, D., Bain, D. E., Williams, R., and Smith, J. C. (2009). "Vessel traffic disrupts the foraging behavior of southern resident killer whales Orcinus orca," Endang. Spec. Res. 6, 211-221. 
Mann, D., Hill-Cook, M., Manire, C., Greenhow, D., Montie, E. W., Powell, J., Wells, R., Bauer, G., Cunningham-Smith, P., Lingenfelser, R., Jr., DiGiovanni, R., Stone, A., Brodsky, M., Stevens, R., Kieffer, G., and Hoetjes, P. (2010). "Hearing loss in stranded odontocete dolphins and whales," PLoS One 5, e13824.

Mooney, T. A., Castellote, M., Hobbs, R. C., Quakenbush, L., Goertz, C., and Gaglione, E. (2016). "Measuring hearing in wild beluga whales," in The Effects of Noise on Aquatic Life, edited by A. N. Popper and A. D. Hawkins (Springer Science+Business Media, New York), pp. 729-736.

Mooney, T. A., Castellote, M., Jones, I., Quakenbush, L., Hobbs, R. C., Gaglione, E., and Goertz, C. E. (2018a). "Local environmental soundscapes relative to hearing sensitivity in beluga whales (Delphinapterus leucas)," J. Ecoacoust. 2, QZD9Z5.

Mooney, T. A., Castellote, M., Quakenbush, L., Hobbs, R., Gaglione, E., and Goertz, C. (2018b). "Variation in hearing within a wild population of beluga whales (Delphinapterus leucas)," J. Exp. Biol. 221, jeb171959.

Mooney, T. A., Hanlon, R. T., Christensen-Dalsgaard, J., Madsen, P. T., Ketten, D. R., and Nachtigall, P. E. (2010). "Sound detection by the longfin squid (Loligo pealeii) studied with auditory evoked potentials: Sensitivity to low-frequency particle motion and not pressure," J. Exp. Biol. 213, 3748-3759.

Mooney, T. A., Nachtigall, P. E., Breese, M., Vlachos, S., and Au, W. W. L. (2009). "Predicting temporary threshold shifts in a bottlenose dolphin (Tursiops truncatus): The effects of noise level and duration," J. Acoust. Soc. Am. 125, 1816-1826.

Mooney, T. A., Nachtigall, P. E., Castellote, M., Taylor, K. A., Pacini, A. F., and Esteban, J.-A. (2008). "Hearing pathways and directional sensitivity of the beluga whale, Delphinapterus leucas," J. Exp. Mar. Biol. Ecol. 362, 108-116.

Mooney, T. A., Nachtigall, P. E., and Yuen, M. M. L. (2006). "Temporal resolution of the Risso's dolphin, Grampus griseus, auditory system," J. Comp. Physiol. A. 192, 373-380.

Mooney, T. A., Yamato, M., and Branstetter, B. K. (2012). "Hearing in cetaceans: From natural history to experimental biology," Adv. Mar. Biol. 63, 197-246.

Nachtigall, P. E., Mooney, T. A., Taylor, K. A., and Yuen, M. M. L. (2007). "Hearing and auditory evoked potential methods applied to odontocete cetaceans," Aquat. Mamm. 33, 6-13.

Nachtigall, P. E., Yuen, M. M. L., Mooney, T. A., and Taylor, K. A. (2005). "Hearing measurements from a stranded infant Risso's dolphin, Grampus griseus,” J. Exp. Biol. 208, 4181-4188.

National Marine Fisheries Service (2008). "Endangered and Threatened Species; Endangered Status for the Cook Inlet Beluga Whale," Fed. Regist. 224, 62919-62930.
Nowacek, D. P., Thorne, L. H., Johnston, D. W., and Tyack, P. L. (2007). "Responses of cetaceans to anthropogenic noise," Mammal Rev. 37, 81-115.

Ohlemiller, K. K., Jones, S. M., and Johnson, K. R. (2016). "Application of mouse models to research in hearing and balance," J. Assoc. Res. Otolaryngol. 17, 493-523.

Pacini, A. F., Nachtigall, P. E., Kloepper, L. N., Linnenschmidt, M., Sogorb, A., and Matias, S. (2010). "Audiogram of a formerly stranded long-finned pilot whale (Globicephala melas) measured using auditory evoked potentials," J. Exp. Biol. 213, 3138-3143.

Ryan, M. J., Perrill, S. A., and Wilczynski, W. (1992). "Auditory tuning and call frequency predict population-based mating preferences in the cricket frog, Acris crepitans," Am. Nat. 139, 1370-1383.

Shelden, K., and Wade, P. (2019). "Aerial surveys, distribution, abundance, and trend of belugas (Delphinapterus leucas) in Cook Inlet, Alaska, June 2018," AFSC Processed Report 2019-09.

Small, R. J., Brost, B., Hooten, M., Castellote, M., and Mondragon, J. (2017). "Potential for spatial displacement of Cook Inlet beluga whales by anthropogenic noise in critical habitat," Endang. Spec. Res. 32, 43-57.

Southall, B. L., Bowles, A. E., Ellison, W. T., Finneran, J. J., Gentry, R. L., Greene, C. R., Jr., Kastak, D., Ketten, D. R., Miller, J. H., Nachtigall, P. E., Richardson, W. J., Thomas, J. A., and Tyack, P. L. (2008). "Marine mammal noise exposure criteria: Initial scientific recommendations," Aquat. Mamm. 33, 411-522.

Supin, A. Y., and Popov, V. V. (1995). "Envelope-following response and modulation rate transfer function in the dolphin's auditory system," Hear. Res. 92, 38-45.

Supin, A. Y., Popov, V. V., and Mass, A. M. (2001). The Sensory Physiology of Aquatic Mammals (Kluwer Academic Publishers, Boston).

Trickey, J. S., Branstetter, B. K., and Finneran, J. J. (2010). "Auditory masking of a $10 \mathrm{kHz}$ tone with environmental, comodulated, and Gaussian noise in bottlenose dolphins (Tursiops truncatus)," J. Acoust. Soc. Am. 128, 3799-3804.

Wisniewska, D. M., Johnson, M., Teilmann, J., Siebert, U., Galatius, A., Dietz, R., and Madsen, P. T. (2018). "High rates of vessel noise disrupt foraging in wild harbour porpoises (Phocoena phocoena)," Proc. R. Soc. B: Biol. Sci. 285, 20172314.

Witte, K., Farris, H. E., Ryan, M. J., and Wilczynski, W. (2005). "How cricket frog females deal with a noisy world: Habitat-related differences in auditory tuning," Behav. Ecol. 16, 571-579.

Yuen, M. M. L., Nachtigall, P. E., Breese, M., and Supin, A. Y. (2005). "Behavioral and auditory evoked potential audiograms of a false killer whale (Pseudorca crassidens)," J. Acoust. Soc. Am. 118, 2688-2695. 